\title{
Time Series Analysis of Industrial Electricity Consumption in Nigeria Using Harvey Model and Autoregressive Model
}

\author{
Ogungbemi Emmanuel Oluropo ${ }^{1}$, Edet Joseph Archibong ${ }^{2}$, Nsikak John Affia ${ }^{3}$ \\ ${ }^{1}$ Department of Electrical/Electronic and Computer Engineering, University of Uyo, Nigeria \\ ${ }^{2}$ Department of Physic, University of Uyo, Uyo, Nigeria \\ ${ }^{3}$ Department of Electrical/Electronic Engineering, Akwa Ibom State Polytechnic, Ikot Osura Ikot Ekpene, Nigeria
}

Email address:

gentlejayy@yahoo.com (N. J. Affia)

\section{To cite this article:}

Ogungbemi Emmanuel Oluropo, Edet Joseph Archibong, Nsikak John Affia. Time Series Analysis of Industrial Electricity Consumption in Nigeria Using Harvey Model and Autoregressive Model. International Journal of Energy and Power Engineering.

Vol. 6, No. 3, 2017, pp. 40-46. doi: 10.11648/j.ijepe.20170603.14

Received: January 3, 2017; Accepted: January 18, 2017; Published: June 27, 2017

\begin{abstract}
In this paper time series modeling and forecasting of industrial electricity consumption in Nigeria is presented. Specifically, Harvey Model and Autoregressive Model, (AR) are used. The data used are obtained from Central Bank of Nigeria (CBN) Statistical Bulletin for industrial electricity consumption ranging from 1979-2014. The results shows that Harvey Model has $\left(\mathrm{r}^{2}\right)=80.1 \%$ and RMSE $=65.2513$ whereas Autoregressive Model has $\left(\mathrm{r}^{2}\right)=50.1 \%$ and RMSE $=71.3985$. Obviously, Harvey model has better prediction accuracy than the AR model. The Harvey model was then used to forecast industrial electricity consumption in Nigeria for the next 15 years (from 2015 to 2029). According to the forecast result by the year 2029 the industrial consumption of Nigeria will stand at $539.65 \mathrm{MW} / \mathrm{h}$ as against $468.18 \mathrm{MW} / \mathrm{h}$ in 2015.
\end{abstract}

Keywords: Time Series Analysis, Industrial Electricity Consumption, Forecasting, Harvey Model, Autoregressive Model

\section{Introduction}

Across the globe, heavy dependence on electricity results in high power demand and hence it requires planning of resources of electricity well in advance to ensure a continuous supply of electricity both now and in the future [1-4]. Therefore, modelling and forecasting of electricity is one of the most important aspects of electric utility planning [5-11]. This requires careful measurement and observation of the patterns of electricity use and its prediction into the future.

Studies have shown that industrial power consumption can be related to the level of industrialization and productivity of a nation [12-14]. Also, effective power supply can also boost the economy of a nation. However, over the years, Nigeria has had perennial short fall in power supply [15-17]. Equally the industrial sector has been affected by this poor power supply and that has affected the productivity of the industrial sector. Accordingly, in this study, the focus is on modeling and forecasting the industrial power consumption in Nigeria.
A large variety of mathematical methods and ideas have been used for energy demand forecasting [18-20]. The quality of the demand forecast methods depends significantly on the availability of historical consumption data as well as on the knowledge about the main influence parameters on the energy consumption. These factors also determine the selection of the best suitable forecast tool. Generally there is no 'best' method. Particularly, data from 1979-2014 and two time series models are used for the modelling and forecasting of industrial electricity consumption in Nigeria. The modelling results are interpreted by statistical tests. The focus of the investigation lies in the application of the selected regression models in predicting and forecasting the industrial electricity demand in Nigeria.

\section{Theoretical Background}

Two (2) time series models, Harvey model [22-24] and Autoregressive model [24 are considered in this paper and the best model is used to forecast the industrial electricity consumption for the period of 15 years $(2015-2029)$ [30]. The best model is selected based on statistical prediction 
performance values.

\subsection{The Harvey Model}

Electricity consumption based on Harvey model is generally given as:

$$
f(t)=\alpha\left(1+\beta e^{\gamma t}\right)^{k}
$$

The Harvey model is based on the simple modified exponential. The proposed model is given as:

$$
\begin{aligned}
& \ln y_{t}=\rho \ln Y_{t-1}+\delta+\gamma t+\varepsilon_{t} \\
& t=2, . ., T
\end{aligned}
$$

Where $\rho=\frac{k-1}{k}, \quad \delta=\ln \left(k \beta \alpha^{1 / k} \gamma\right)$, and $\rho, \beta$ and $\gamma$ are the parameters of the model to be estimated. $\varepsilon_{i}$ is the error term with mean zero and constant variance.

$$
\ln y_{t}=a \ln Y_{t-1}+b+c_{t}+\varepsilon_{i}
$$

$\mathrm{y}_{\mathrm{t}}=Y_{t}-Y_{t-1}$. Substituting for $\mathrm{y}_{\mathrm{t}}$ in equation (3) gives;

$$
\begin{gathered}
\ln \left(Y_{t}-Y_{t-1}\right)=a \ln \left(Y_{t-1}\right)+b+c t+\varepsilon_{t} \\
\ln \left(\frac{Y_{t}}{Y_{t-1}}\right)=a \ln \left(Y_{t-1}\right)+b+c t+\varepsilon_{t}
\end{gathered}
$$

Let $r_{i}=\ln \left(\frac{Y_{t}}{Y_{t-1}}\right)$ and $S_{t}=\operatorname{In} Y_{t-1}$ then equation becomes:

$$
r_{t}=a S_{t}+b+c t+\varepsilon
$$

The error is

$$
\varepsilon_{i}=\sum_{i=1}^{n}\left(r_{i}-a S_{i}-b-c t_{i}\right)
$$

Let $u$ be the sum of squares of the error, then;

$$
\begin{gathered}
u=\sum_{i=1}^{n}\left(r_{i}-a S_{i}-b-c t_{i}\right)^{2} \\
\frac{\partial u}{\partial a}=-2\left[\sum_{i=1}^{n} r_{i} s_{i}-a \sum_{i=1}^{n} s_{i}^{2}-b \sum_{i=1}^{n} s_{i}-c \sum_{i=1}^{n} t_{i}\right] \\
\frac{\partial u}{\partial b}=-2\left[\sum_{i=1}^{n} r_{i} s-a \sum_{i=1}^{n} s_{i}-n b-c \sum_{i=1}^{n} t_{i}\right] \\
\frac{\partial u}{\partial c}=-2\left[\sum_{i=1}^{n} r_{i} t_{i}-a \sum_{i=1}^{n} s_{i} t_{i}-b \sum_{i=1}^{n} t_{i}-c \sum_{i=1}^{n} t_{i}^{2}\right]
\end{gathered}
$$

If $\frac{\partial u}{\partial a}, \frac{\partial u}{\partial b}$ and $\frac{\partial u}{\partial c}$ are set to zero and rearrange the equations will give:

$$
\begin{aligned}
& a \sum_{i=1}^{n} S_{i}^{2}+b \sum_{i=1}^{n} S_{i}+c \sum_{i=1}^{n} s_{i} t_{i}=\sum_{i=1}^{n} r_{i} s_{i} \\
& a \sum_{i=1}^{n} S_{i}+n b+c \sum_{i=1}^{n} t_{i}=\sum_{i=1}^{n} r_{i} \\
& a \sum_{i=1}^{n} S_{i} t_{i}+b \sum_{i=1}^{n} t_{i}+c \sum_{i=1}^{n} t_{i}^{2}=\sum_{i=1}^{n} r_{i} t_{i}
\end{aligned}
$$

In matrix form, equation (10) can be expressed as:

$$
\begin{aligned}
& \left(\begin{array}{ccc}
\sum_{i=1}^{n} s_{i}^{2} & \sum_{i=1}^{n} s_{i} & \sum_{i=1}^{n} s_{i} t_{i} \\
\sum_{i=1}^{n} s_{i} & n & \sum_{i=1}^{n} t_{i} \\
\sum_{i=1}^{n} s_{i} t_{i} & \sum_{i=1}^{n} t_{i} & \sum_{i=1}^{n} t_{i}^{2}
\end{array}\right)\left(\begin{array}{l}
a \\
b \\
c
\end{array}\right)=\left(\begin{array}{l}
\sum_{i=1}^{n} r_{i} s_{i} \\
\sum_{i=1}^{n} r_{i} \\
\sum_{i=1}^{n} r_{i} t_{i}
\end{array}\right) \\
& \left(\begin{array}{l}
a \\
b \\
c
\end{array}\right)=\left(\begin{array}{ccc}
\sum_{i=1}^{n} s_{i}^{2} & \sum_{i=1}^{n} s_{i} & \sum_{i=1}^{n} s_{i} t_{i} \\
\sum_{i=1}^{n} s_{i} & n & \sum_{i=1}^{n} t_{i} \\
\sum_{i=1}^{n} s_{i} t_{i} & \sum_{i=1}^{n} t_{i} & \sum_{i=1}^{n} t_{i}^{2}
\end{array}\right)^{-1}\left(\begin{array}{l}
\sum_{i=1}^{n} r_{i} s_{i} \\
\sum_{i=1}^{n} r_{i} \\
\sum_{i=1}^{n} r_{i} t_{i}
\end{array}\right)
\end{aligned}
$$

The solution of equation (12) gives the parameters of the model.

\subsection{The Autoregressive (AR) Model}

$$
Y_{t}=\beta_{0}+\beta_{1} Y_{t-1}+\varepsilon_{t}
$$

Where $\beta_{0}$ and $\beta_{1}$ are the parameters of the model, $\varepsilon_{t}$ is the error term with mean zero and the parameter constant variance. The $\beta_{0}$ and $\beta_{1}$ can be estimated by the method of least square. From equation 13

$$
\begin{gathered}
\varepsilon_{t}=Y_{t}-\beta_{0}-\beta_{1} Y_{t-1} \\
\varepsilon_{t}^{2}=\left(Y_{t}-\beta_{0}-\beta_{1} Y_{t-1}\right)^{2}
\end{gathered}
$$

Let

$$
S=\sum_{\mathrm{t}=1}^{\mathrm{n}} \varepsilon_{\mathrm{t}}^{2}=\sum_{t=1}^{n}\left(Y_{t}-\beta_{0}-\beta_{1} Y_{t-1}\right)^{2}
$$

Taking the derivatives of equation (16) with respect to $\beta_{0}$ and $\beta_{1}$ gives;

$$
\begin{gathered}
\frac{\partial S}{\partial \beta_{0}}=2(-1) \sum_{t=1}^{n}\left(Y_{t}-\beta_{0}-\beta_{1} Y_{t-1}\right) \\
\frac{\partial S}{\partial \beta_{1}}=2(-1) \sum_{t=1}^{n}\left(\left[Y_{t-1}\left(Y_{t}-\beta_{0}-\beta_{1} Y_{t-1}\right)\right]\right) \\
\frac{\partial S}{\partial \beta_{1}}=\sum_{t=2}^{n} Y_{t-1} Y_{t}-\beta_{0} \sum_{t=2}^{n} Y_{t-1}-\beta_{1} \sum_{t=2}^{n} Y_{t-1}^{2}
\end{gathered}
$$


To obtain an equation for the parameters, set $\frac{\partial S}{\partial \beta_{0}}$ and $\frac{\partial S}{\partial \beta_{1}}$ to zero.

$$
\begin{aligned}
& \sum_{t=1}^{n} Y_{t}-n \beta_{0}-\beta_{1} \sum_{t=2}^{n} Y_{t-1}=0 \\
& \sum_{t=2}^{n} Y_{t-1} Y_{t}-\beta_{0} \sum_{t=2}^{n} Y_{t-1}-\beta_{1} \sum_{t=2}^{n} Y_{t-1}^{2}=0 \\
& n \beta_{0}+\beta_{1} \sum_{t=2}^{n} Y_{t-1}=\sum_{t=1}^{n} Y_{t} \\
& \beta_{0} \sum_{t=1}^{n} Y_{t-1}+\beta_{1} \sum_{t=2}^{n} Y_{t-1}^{2}=\sum_{t=1}^{n} Y_{t-1} Y_{t} \\
& \left(\begin{array}{cc}
n & \sum_{t=2}^{n} y_{t-1} \\
\sum_{t=2}^{n} y_{t-1} & \sum_{t=2}^{n} y_{t-1}^{2}
\end{array}\right)\left(\begin{array}{l}
\beta_{0} \\
\beta_{1}
\end{array}\right)=\left(\begin{array}{l}
\sum_{t=1}^{n} y_{t} \\
\sum_{t=2}^{n} y_{t-1} y_{t}
\end{array}\right) \\
& \text { Let } \mathrm{p}=\left(\begin{array}{ll}
n & \sum_{t=2}^{n} y_{t-1} \\
\sum_{t=2}^{n} y_{t-1} & \sum_{t=2}^{n} y_{t-1}^{2}
\end{array}\right), \beta=\left(\begin{array}{l}
\beta_{0} \\
\beta_{1}
\end{array}\right) \text { and } \\
& \gamma=\left(\begin{array}{l}
\sum_{t=1}^{n} y_{t} \\
\sum_{t=2}^{n} y_{t-1} y_{t}
\end{array}\right) \\
& p \beta=\gamma \\
& \beta=p^{-1} Y
\end{aligned}
$$

\subsection{Statistical Tests for the Forecasting Models}

\subsubsection{Coefficient of Determination $\left(r^{2}\right)$}

The coefficient of determination $r^{2}$ is used to determine the effectiveness of using the model in forecasting. It gives the coefficient of the total variance in the department variable explained by the model.

$$
r^{2}=\frac{\sum_{t=1}^{n}\left(Y_{t}-\bar{Y}\right)^{2}}{\sum_{t=1}^{n}\left(Y_{t}-\bar{Y}\right)^{2}}
$$

Where, $\hat{Y}_{t}$ and $Y_{t}$ are the estimated and actual value of discharge.

Where $\mathrm{n}$ is the number of observation or data point.

\subsubsection{Root Mean Square Error (RMSE)}

$$
R M S E=\frac{1}{n} \sum_{i=1}^{n}\left(Y_{t}-\hat{Y}_{t}\right)^{2}
$$

\section{Results and Discussions}

\subsection{Harvey Model}

Table 1. Results for Industrial Electricity Consumption Estimation using Harvey Model.

\begin{tabular}{lllll}
\hline Parameter & Coefficient & Standard errors & $\mathbf{r}^{2}$ & RMSE \\
\hline $\mathrm{a}$ & -0.5764 & 0.1632 & 0.80 & 65.2513 \\
$\mathrm{~b}$ & -24.346 & 10.4374 & & \\
$\mathrm{c}$ & 0.01382 & 0.0055 & & \\
\hline
\end{tabular}

The Harvey Model is:

$$
\begin{gathered}
\ln \left(\frac{Y_{t}}{Y_{t-1}}\right)=-0.5764 \ln Y_{t-1}-24.346+0.01382 t \\
\operatorname{In}\left(\frac{Y_{t}}{Y_{t-1}}\right)=-24.346-0.5764 \ln Y_{t-1}+0.01382 t \\
Y_{t}=Y_{t-1} e^{\left(-24.3446-0.5764 \ln Y_{t-1}+0.013282 t\right)}
\end{gathered}
$$

From Table 1, with $\mathrm{r}^{2}$ value of 0.80 , it means that the Harvey model accounted for $80 \%$ of the variation in industrial electricity consumption. Moreover, The coefficient of $t$ is positive $(\mathrm{c}=0.01382)$ which means that industrial consumption increases with time. Table 2 and figure 1 present the actual and predicted value of industrial electricity consumption based on Harvey model.

Table 2. Actual and Predicted Industrial Electricity Consumption using HarveyModel.

\begin{tabular}{llllllll}
\hline & \multirow{2}{*}{ Industrial electricity consumption $(\mathbf{M W} / \mathbf{h})$} & \multicolumn{3}{l}{ Industrial electricity consumption } \\
\cline { 6 - 8 } & Year & Actual & Predicted & S/N & Year & Actual & Predicted \\
\hline S/N & 1979 & 160.3 & 169.98 & 19 & 1997 & 236.8 & 258.3 \\
2 & 1980 & 199.7 & 173.55 & 20 & 1998 & 218.9 & 262.6 \\
3 & 1981 & 121 & 193.15 & 21 & 1999 & 191.8 & 257.53 \\
4 & 1982 & 262 & 158.35 & 22 & 2000 & 223.8 & 246.88 \\
5 & 1983 & 254.4 & 222.79 & 23 & 2001 & 241.9 & 267.24 \\
6 & 1984 & 217.2 & 223.09 & 24 & 2002 & 146.2 & 280.05 \\
7 & 1985 & 259.8 & 211.53 & 25 & 2003 & 196 & 229.35 \\
8 & 1986 & 280.5 & 231.39 & 26 & 2004 & 398 & 263.32 \\
9 & 1987 & 294.1 & 242.36 & 27 & 2005 & 182.3 & 360.52 \\
\hline
\end{tabular}




\begin{tabular}{|c|c|c|c|c|c|c|c|}
\hline \multirow[b]{2}{*}{$\mathbf{S} / \mathbf{N}$} & \multicolumn{3}{|c|}{ Industrial electricity consumption (MW/h) } & \multirow[b]{2}{*}{$\mathbf{S} / \mathbf{N}$} & \multicolumn{3}{|c|}{$\begin{array}{l}\text { Industrial electricity consumption } \\
\text { (MW/h) }\end{array}$} \\
\hline & Year & Actual & Predicted & & Year & Actual & Predicted \\
\hline 10 & 1988 & 291.1 & 250.72 & 28 & 2006 & 383.44 & 262.51 \\
\hline 11 & 1989 & 257.9 & 253.1 & 29 & 2007 & 494.01 & 364.81 \\
\hline 12 & 1990 & 230.1 & 243.78 & 30 & 2008 & 421.6 & 411.84 \\
\hline 13 & 1991 & 253.7 & 235.5 & 31 & 2009 & 428.954 & 390.43 \\
\hline 14 & 1992 & 245.3 & 248.87 & 32 & 2010 & 395.591 & 398.77 \\
\hline 15 & 1993 & 237.4 & 248.76 & 33 & 2011 & 426.37 & 390.68 \\
\hline 16 & 1994 & 233.3 & 248.75 & 34 & 2012 & 457.92 & 408.9 \\
\hline 17 & 1995 & 218.7 & 250.35 & 35 & 2013 & 518.7 & 427.33 \\
\hline 18 & 1996 & 235.3 & 246.97 & 36 & 2014 & 594.48 & 456.79 \\
\hline
\end{tabular}

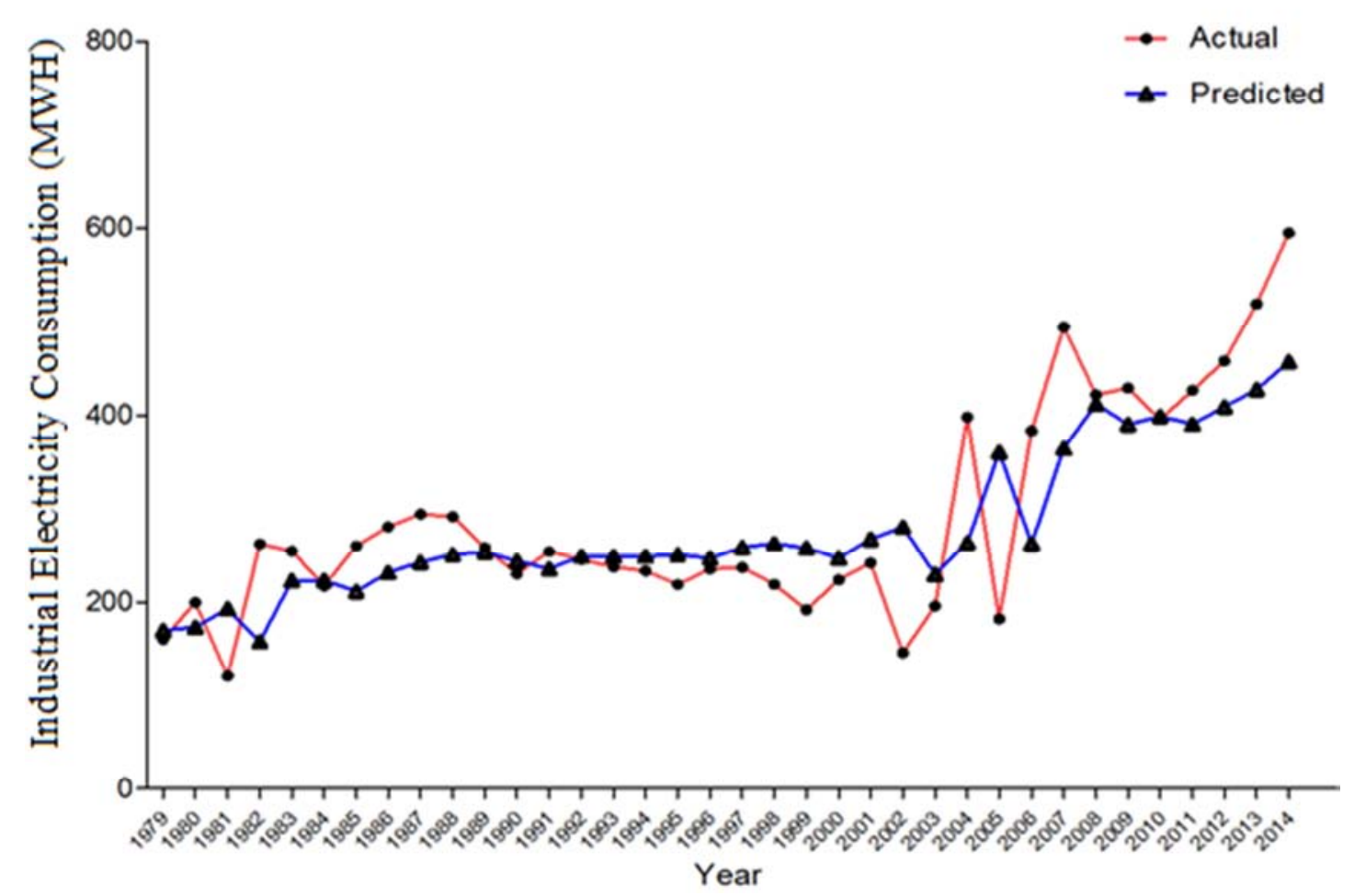

Figure 1. Actual and Predicted Industrial Electricity Consumption in Nigeria between 1979-2014.

\subsection{Autoregressive Model}

Table 3. Results for Industrial Electricity Consumption Estimation using Autoregressive model.

\begin{tabular}{lllll}
\hline Variables & Coefficient & Standard Error & $\mathbf{r}^{2}$ & RMSE \\
\hline $\boldsymbol{\mu}_{0}$ & 76.4348 & 95.8456 & 0.501 & 71.3985 \\
$\boldsymbol{\mu}_{1}$ & 0.7552 & 0.1234 & & \\
\hline
\end{tabular}

RMSE $=$ Root Mean Square Error.

Based on the model parameters shown in Table 3, the Autoregressive model for industrial electricity consumption is:

$$
\hat{Y}_{t}=76.4348+0.7552 Y_{t-1}
$$

Where, $\hat{Y}_{t}$ is the estimated industrial electricity consumption.

The model gave $\mathrm{r}^{2}$ of 0.5010 which means that Autoregressive model was able to explained 50.10 percent of the variance in industrial electricity consumption (Table 3). The coefficient of $Y_{t-1}$ is positive (0.7552) which means that industrial electricity consumption in Nigeria increases with time. The value of the actual and estimated industrial electricity consumption using the Autoregressive model is shown in Table 4 and figure 2.

Table 5 reveals that the Harvey model predicted better than the Autoregressive model as it gave higher value of coefficient of determination $\left(\mathrm{r}^{2}=80.0 \%\right)$ and lower Root Mean Square Error ( 65.2513).

Table 4. Actual and Predicted Industrial Electricity Consumption Using Autoregressive model.

\begin{tabular}{lllllll}
\hline & & \multicolumn{2}{l}{ Industrial Electricity } & Consumption (MW/h) & \multicolumn{2}{c}{ Industrial Electricity Consumption (MW/h) } \\
\hline S/N & Year & Actual & Predicted & S/N & Year & Actual \\
\hline 1 & 1979 & 160.3 & 195.53 & 19 & 1997 & 236.8 \\
2 & 1980 & 199.7 & 197.49 & 20 & 1998 & 218.9 \\
\hline
\end{tabular}




\begin{tabular}{llllllll}
\hline & \multicolumn{3}{l}{ Industrial Electricity Consumption $(\mathbf{M W} / \mathbf{h})$} & & & \multicolumn{2}{c}{ Industrial Electricity Consumption (MW/h) } \\
\hline S/N & Year & Actual & Predicted & S/N & Year & Actual & Predicted \\
\hline 3 & 1981 & 121 & 227.25 & 21 & 1999 & 191.8 & 241.75 \\
4 & 1982 & 262 & 167.81 & 22 & 2000 & 223.8 & 221.28 \\
5 & 1983 & 254.4 & 274.29 & 23 & 2001 & 241.9 & 245.45 \\
6 & 1984 & 217.2 & 268.55 & 24 & 2002 & 146.2 & 259.11 \\
7 & 1985 & 259.8 & 240.46 & 25 & 2003 & 196 & 186.84 \\
8 & 1986 & 280.5 & 272.63 & 26 & 2004 & 398 & 224.45 \\
9 & 1987 & 294.1 & 288.27 & 27 & 2005 & 182.3 & 377 \\
10 & 1988 & 291.1 & 298.54 & 28 & 2006 & 383.438 & 214.11 \\
11 & 1989 & 257.9 & 296.27 & 29 & 2007 & 494.01 & 366 \\
12 & 1990 & 230.1 & 271.2 & 30 & 2008 & 421.6 & 449.51 \\
13 & 1991 & 253.7 & 250.2 & 31 & 2009 & 428.954 & 394.82 \\
14 & 1992 & 245.3 & 268.03 & 32 & 2010 & 395.591 & 400.38 \\
15 & 1993 & 237.4 & 261.68 & 33 & 2011 & 426.37 & 375.18 \\
16 & 1994 & 233.3 & 255.72 & 34 & 2012 & 457.92 & 398.42 \\
17 & 1995 & 218.7 & 252.62 & 35 & 2013 & 518.7 & 422.25 \\
18 & 1996 & 235.3 & 241.59 & 36 & 2014 & 594.48 & 468.15 \\
\hline
\end{tabular}

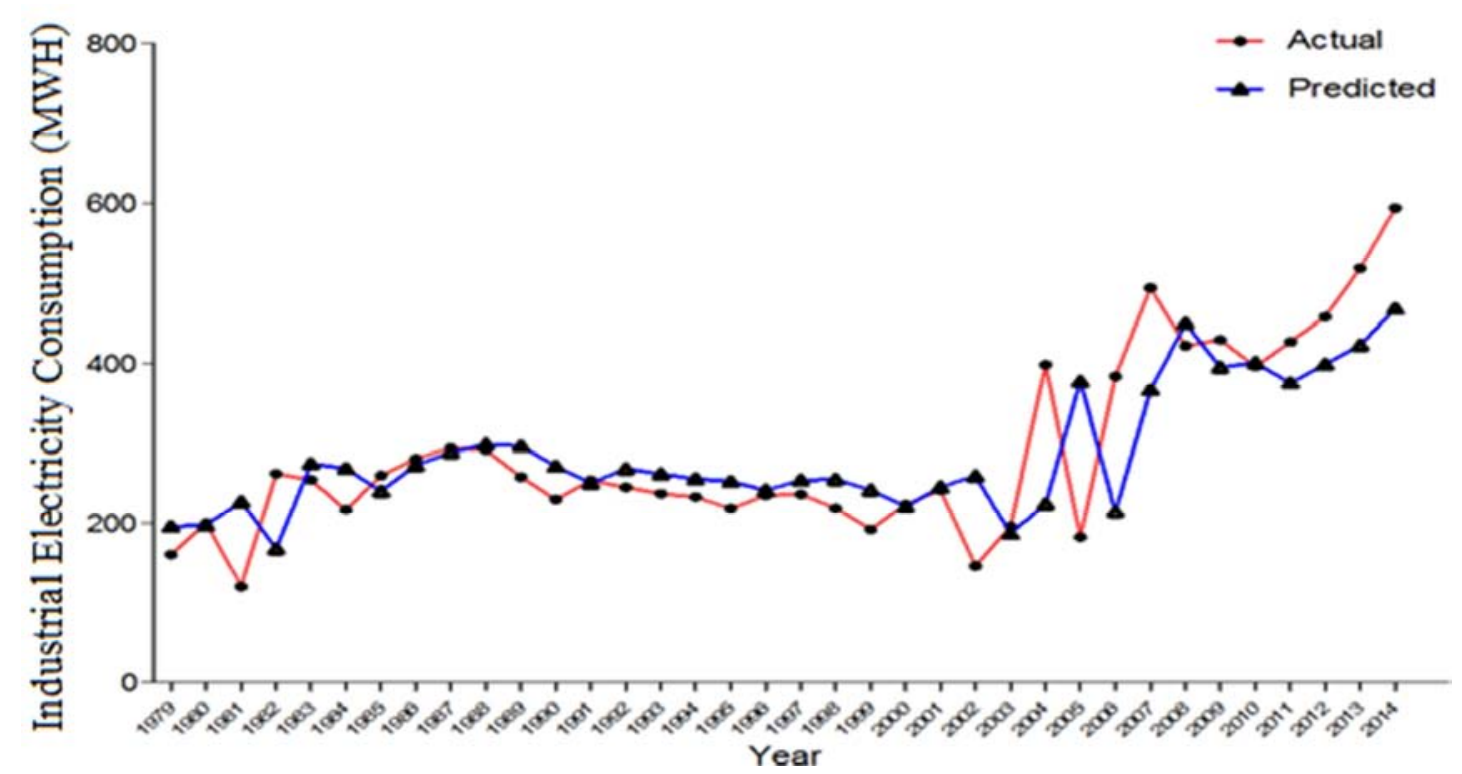

Figure 2. Actual and Predicted Industrial Electricity Consumption in Nigeria between 1979-2014 using Autoregressive model.

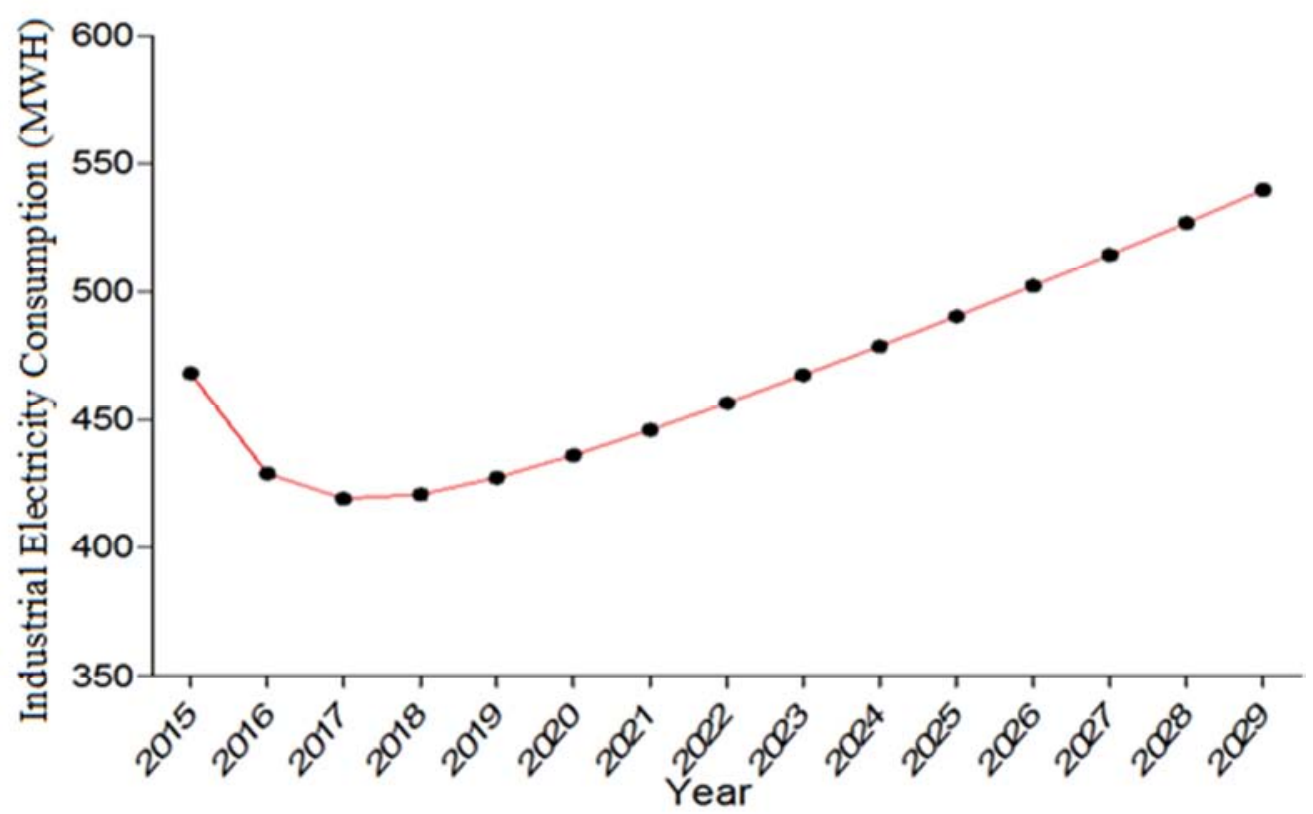

Figure 3. Graph of Forecasted Industrial Electricity Consumption in Nigeria (2015-2029). 
Table 5. Comparison of the Forecasting Accuracy of the Harvey and Autoregressive model.

\begin{tabular}{lll}
\hline Models & $\mathbf{r}^{\mathbf{2}} \mathbf{( \% )}$ & $\mathbf{R M S E}$ \\
\hline Harvey & 80.0 & 65.2513 \\
Autoregressive & 50.1 & 71.3985 \\
\hline
\end{tabular}

\subsection{Forecast of Industrial Electricity Consumption in} Nigeria Using the Best Selected Model (Harvey Model)

Table 6. Forecast of Industrial Electricity Consumption using the Harvey Models (2015-2029).

\begin{tabular}{lll}
\hline S/N & Year & Forecast of industrial Electricity consumption (MW/h) \\
\hline 1 & 2015 & 468.18 \\
2 & 2016 & 429.01 \\
3 & 2017 & 419.17 \\
4 & 2018 & 420.84 \\
5 & 2019 & 427.4 \\
6 & 2020 & 436.19 \\
7 & 2021 & 446.08 \\
8 & 2022 & 456.6 \\
9 & 2023 & 467.53 \\
10 & 2024 & 478.81 \\
11 & 2025 & 490.39 \\
12 & 2026 & 502.26 \\
13 & 2027 & 514.42 \\
14 & 2028 & 526.89 \\
15 & 2029 & 539.65 \\
\hline
\end{tabular}

The forecasting of electricity demand is obtained from the Harvey model by extrapolating the data from the year 2015 to 2029. The forecast values in Table 6 and figure 3 clearly indicate that the demand for electricity in Nigeria is continuously increasing. The industrial demand for electricity in Nigeria will increase from $468.18 \mathrm{MW} / \mathrm{h}$ in 2015 to 539.65 $\mathrm{MW} / \mathrm{h}$ in 2029 which amounts to about $15.3 \%$ increase.

\section{Conclusion}

Modeling and forecasting of industrial electricity consumption in Nigeria using two time series models is presented. The models are Harvey Model and Autoregressive Model. In the paper, data from 1979-2014 is use to predict the industrial electricity consumption and based on the results obtained Harvey model with better prediction accuracy is selected and used to forecast the industrial electricity consumption for the next fifteen years.

\section{References}

[1] Nachet, S., \& Aoun, M. C. (2015). The Saudi electricity sector: pressing issues and challenges.

[2] Belt, J. (2009). The electric power sector in Cuba: Potential ways to increase efficiency and sustainability. In Cuba's Energy Future: Strategic Approaches to Cooperation. Brookings Washington.

[3] Lin, B. Q. (2003). Electricity demand in the People's Republic of China: investment requirement and environmental impact.

[4] Matek, B., \& Gawell, K. (2015). The benefits of baseload renewables: a misunderstood energy technology. The Electricity Journal, 28 (2), 101-112.

[5] Swaroop, R., \& HUSSEIN, A. A. (2012). Load Forecasting For Power System Planning And Operation Using Artificial Neural Network At Al Batinah Region Oman. Journal of Engineering Science and Technology, 7 (4), 498-504.

[6] Fahad, M. U., \& Arbab, N. (2014). Factor Affecting Short Term Load Forecasting. Journal of Clean Energy Technologies, 2 (4), 305-309.

[7] Paul, R. (2015). Load Forecasting Using Linear Regression And Artificial Neural Networks (Doctoral dissertation, NATIONAL INSTITUTE OF TECHNOLOGY WARANGAL).

[8] Feinberg, E. A., \& Genethliou, D. (2005). Load forecasting. In Applied mathematics for restructured electric power systems (pp. 269-285). Springer US.

[9] BHARDWAJ, S. (2014). ANALYSING LOAD FORECASTING TECHNIQUES (Doctoral dissertation, VIT University VELLORE).

[10] Demir, A. (2014). Elaboration of Electricity Energy for Production-Consumption Relation of Northern-Iraq for the Future Expectations. International Journal of Academic Research in Economics and Management Sciences, 3 (5), 101.

[11] Özdemir, V. (2014). A Future Projection of Turkey's Energy Intensity. Energy Sources, Part B: Economics, Planning, and Policy, 9 (1), 1-8.

[12] Kniivilä, M. (2007). Industrial development and economic growth: Implications for poverty reduction and income inequality. Industrial Development for the 21st Century: Sustainable Development Perspectives, 295-333.

[13] Shihab, M. (2001). Economic Development in the UAE. United Arab Emirates: a new perspective, 249-59.

[14] Ackah, C., Adjasi, C., \& Turkson, F. (2014). Scoping study on the evolution of industry in Ghana. World Institute for Development Economics Research (WIDER) working paper No, $75,1-40$.

[15] Ogunleye, E. K. (2016). Political economy of Nigerian power sector reform (No. UNU-WIDER Research Paper wp2016-009). World Institute for Development Economic Research (UNU-WIDER).

[16] Awosope, C. A. (2015). Nigeria Electricity Industry: Issues, Challenges and Solutions.

[17] Odior, A. O., Oyawale, F. A., \& Ovuworie, G. C. (2010). Some operations of electric power supply system in Benin City area of Nigeria. Am J Sci Ind Res, 1 (3), 636-642.

[18] Fischer, M. (2008). Modeling and Forecasting energy demand: Principles and difficulties, In Management of Weather and Climate Risk in the Energy Industry, Troccoli, A. (Ed.), pp. 207-226, 2008.

[19] Feinberg, E. A., \& Genethliou, D. (2005). Load forecasting. In Applied mathematics for restructured electric power systems (pp. 269-285). Springer US.

[20] Schellong, W. (2011). Energy demand analysis and forecast. INTECH Open Access Publisher. 
[21] Oyelami, B. O., \& adedoyin Adewumi, A. (2014). Models for Forecasting the Demand and Supply of Electricity in Nigeria. American Journal of Modeling and Optimization, 2 (1), 25-33.

[22] Mohamed, Z., \& Bodger, P. (2005). A comparison of Logistic and Harvey models for electricity consumption in New Zealand. Technological Forecasting and Social Change, 72 (8), 1030-1043.

[23] Roken, R. M., \& Badri, M. A. (2006). Time Series Models for Forecasting Monthly Electricity Peak Load for Dubai. Chancellor's Undergraduate Research Award.

[24] Nedzingahe, L. (2010). Forecasting models for operational and tactical requirements in electricity consumption: The case of the Ferrochrome Sector in South Africa (Doctoral dissertation, University of Limpopo (Medunsa Campus)).

[25] Nowicka-Zagrajek, J., \& Weron, R. (2002). Modeling electricity loads in California: ARMA models with hyperbolic noise. Signal Processing, 82 (12), 1903-1915.
[26] Hinman, J., \& Hickey, E. (2009). Modeling and forecasting short-term electricity load using regression analysis. Journal of IInstitute for Regulatory Policy Studies [электронный pecypc].

[27] Weron, R., \& Misiorek, A. (2005, May). Forecasting spot electricity prices with time series models. In Proceedings of the European Electricity Market EEM-05 Conference (pp. 133-141).

[28] Cho, H., Goude, Y., Brossat, X., \& Yao, Q. (2013). Modeling and forecasting daily electricity load curves: a hybrid approach. Journal of the American Statistical Association, 108 (501), $7-21$.

[29] Roken, R. M., \& Badri, M. A. (2006). Time Series Models for Forecasting Monthly Electricity Peak Load for Dubai. Chancellor's Undergraduate Research Award.

[30] National Bureau of Statistics (2014). "Nigerian Gross Domestic Product Report, Quarter two 2014", Abuja-Nigeria. 